\title{
A New Species and a Newly Reported Korean Species of the Genus Tiphia (Tiphiidae, Hymenoptera) from Korea and Japan
}

\author{
Jeong-Kyu Kim* and Seung-Pil Han \\ Department of Biological Sciences, Faculty of Science, Hanseo University, \\ Chungcheongnam-do 356-706, Korea
}

\begin{abstract}
A new species, Tiphia fuscopterum Kim and Han, is described based on two specimens collected in Korea and Japan. We also report Tiphia antigenata Allen et Jaynes for the first time in Korea. Tiphia ogurai Tsuneki is synonymized with $T$. antigenata. Detailed descriptions and digital images of these species are provided.
\end{abstract}

Key words: Tiphia fuscopterum, new species, T. antigenat, new to Korea, T. ogurai, new synonym

\section{INTRODUCTION}

In the process of ongoing systematic study of the Korean tiphiid wasps (refer to Han et al., 2007; Han and Kim, 2008), we report two species, Tiphia fuscopterum Kim and Han and T. antigenata, that are new to science and new to Korea, respectively. In addition, we synonymized $T$. ogurai with the latter species based on examination of holotype.

The new species is easily distinguished by the largely fuscous both wings, and polished impunctate emarginated area in the posteromedian part of punctate area of pygidium. Among the species of "koreana-group" (s.l. Allen et Jaynes, 1930), newly recorded Korean species is easily recognized by the sparse brown metasomal bristles.

We here provide descriptions of the two species and digital images for external diagnostic features.

\section{MATERIALS AND METHODS}

Terminology primarily follows Allen and Jaynes (1930) and Tsuneki (1981). All measurements were taken at the maximal portion of the structure being measured. Body length means the length from the anterior margin of head to posterior margin of metasomal tergum II. The abbreviation of BAWL does the ratio of basal width, apical width and length of propodeal areola. We use three comparative terms to explain puncture distribution: sparse (punctures spaced distantly, usually separating one another by two or three times

\footnotetext{
*To whom correspondence should be addressed

Tel: 82-41-660-1349, Fax: 82-41-688-3403
}

E-mail: kwasp@chol.com as long as puncture diameter), moderate (punctures spaced by the puncture diameter), and dense (punctures spaced closely, usually punctures touching one another).

Abbreviations for museum are as follows: USNM, Unites State National Museum, USA; MNHAH, The Museum of Nature and Human Activities, Hyogo, Japan.

\section{SYSTEMATIC ACCOUNTS}

Order Hymenoptera

Family Tiphiidae

Genus Tiphia Fabricius, 1775

${ }^{1}$ *Tiphia fuscopterum Kim and Han, new species (Fig. 1)

Type material. Holotype. 1 우, Cheonggye Mt., Weonji-dong, Seocho-gu, Seoul, 17 Aug. 2007 (J.K. Kim) (Hanseo Univ, Korea). Paratype. 1우, Kanesawamaru no uchi, 24 Aug. 1994 (collector not stated) (Sk. Yamane collection at Kagoshima University, Japan).

Description. Holotype female. Body length $10.8 \mathrm{~mm}$ (Fig. 1A). Clypeus with its lateral apical margin distinctly convex; median apical production trapezium in shape, and its apical margin almost truncate (Fig. 1B). Frontal carina short, only present in lower frons. Pronotal carina lost dorsally, and defined only in lateral face of pronotum. Central groove of pronotal lateral face defined, but shallow and intermittent, not forming a continuous groove (Fig. 1E). Posterior margin of tegula without impressed line. Epicnemial carina strong (highly raised), and complete without interruption. Propodeal areola rectangular, BAWL $1: 0.9: 2$; median carina present 

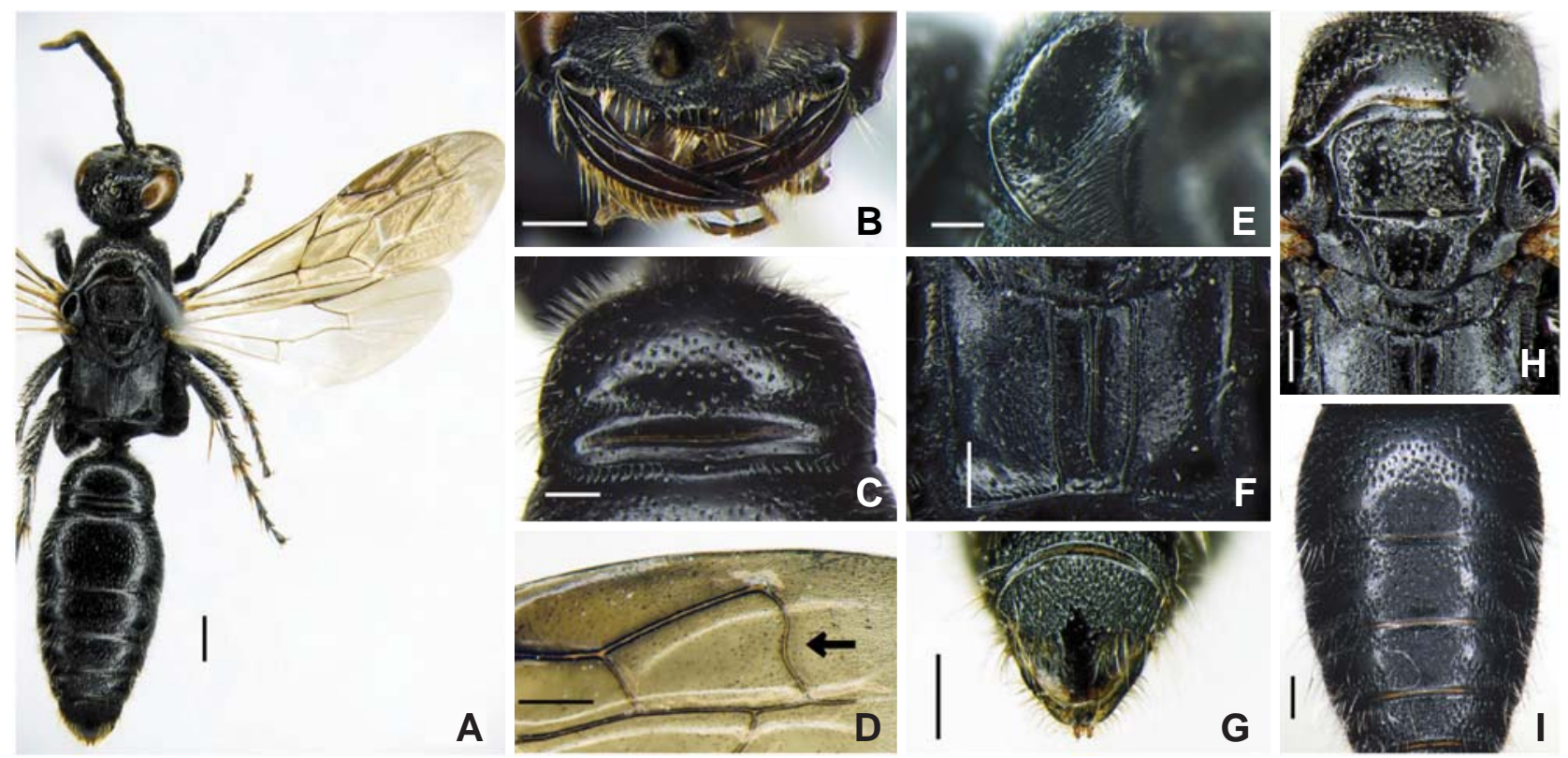

Fig. 1. Tiphia fuscopterum (Holotype, female). A, General habitus; B, Clypeus and mandible; C, Metasomal tergum I showing preapical puncture band; D, Part of forewing, showing sinuous second cubital vein (arrow); E, Lateral face of pronotum; $F$, Propodeal dorsum with areola and straight sublateal carina; G, Pygidium with polished impunctate area; H, Mesosoma, dorsal view; I, Metaso$\mathrm{ma}$, dorsal view. Scale bars $=1 \mathrm{~mm}(\mathrm{~A}), 0.5 \mathrm{~mm}$ (B-I).

in basal 4/5 of areola (Fig. 1F); sublateral carina of propodeal dorsum straight (not sinuate along margin of post-spiracle excavation), but not joining with lateral carina posteriorly; post-spiracle excavation shallow, and its bottom almost flat; median carina of propodeal posterior face short, being developed in lower $1 / 3$ of the face. Metasomal sternum I with obsolete lateral grooves, and without median carina. Lower margin of longer apical spine of hind tibia angled in basal $1 / 3$ where the broadest; shorter one normal spine-like, 3/4 as long as longer one. Hind basitarsus with a groove; outer face of hind basitarsus with two straight, lanceolate spines excluding apical marginal one. Wing as in fig. 1D (arrow): second intercubital vein sinuous; fore wing fuscous except for basal small part; hind wing fuscous (thinner than forewing) in its apical half.

Anterior part of vertex with sparse to moderate punctures irregularly set; posterior part of vertex densely punctate. Larger part of upper frons moderately to densely punctate, but its median part (beneath anterior ocellus) almost impunctate; lower frons densely punctate. Clypeus, except for impunctate median apical part (i.e. produced part), densely punctate. Basal half of pronotal dorsum with moderate punctures (denser in anterior marginal part), and the remaining apical half impunctate and polished; upper half of pronotal lateral face (i.e. upper portion of central groove) microcoriaceous, and lower half finely carinate. Tegula smooth and polished.
Larger part of mesopleuron moderately punctate, and the interspaces microcoriaceous. Mesoscutum, except for almost impunctate lateral parts (at most with several punctures irregularly set), densely punctuate. Scutellum and metanotum with moderate to dense punctures in their marginal parts, but almost impunctate in median parts (Fig. 1H). Propodeal dorsum (excluding areola) somewhat polished, and striate (mainly largely nearby areola) and microcoriaceous, with feeble sparse punctures; upper half of propodeal lateral face with parallel carinae, and lower half microcoriaceous. Metasomal tergum I with sparse small punctures; preapical puncture band being formed by two or three rows of punctures laterally and one row medially (Fig. 1C). Tergum II sparsely punctate, with preapical puncture band being formed by two to three irregular puncture rows. Terga III-IV moderately punctate in it basal half, and impunctate in submedian part before preapical puncture band. The puncture condition of tergum V similar to terga III-IV, but impunctate area reduced medially (Fig. 1I). Pygidium somewhat densely punctate in basal $3 / 5$, and posterior median part of punctuate area with polished impunctate emargination; finely striate in the remaining part (Fig. 1G).

Body black, covered only with whitish bristle and hairs, without brownish bristles in metasomal segments. Mandible reddish brown, and inner face of hind femur reddish black.

Paratype female closely resembles holotype except for the 

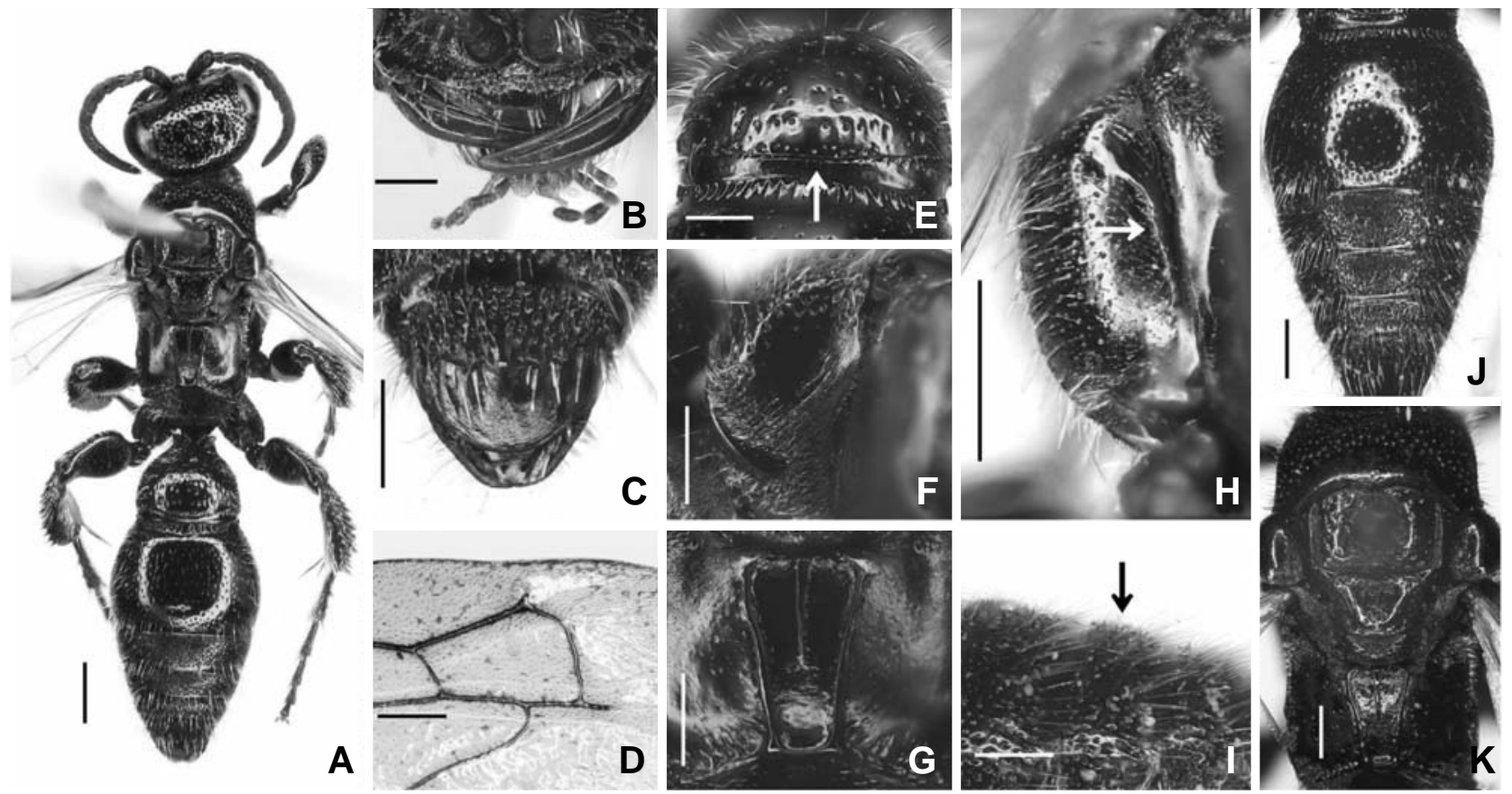

Fig. 2. Tiphia antigenata (female). A, General habitus; B, Clypeus and mandible; C, Pygidium; D, Part of forewing, showing widely round second cubital vein; E, Metasomal tergum I folded preapically (arrow); F, Lateral face of pronotum; G, Propodeal dorsum with areola; $\mathrm{H}$, Mesopleuron with a premarginal groove (arrow); I, Metasomal terga III-IV, short brown bristles (arrow); J, Metasoma, dorsal view; K, Mesosoma, dorsal view. Scale bars=1 mm (A), $0.5 \mathrm{~mm}(\mathrm{~B}-\mathrm{K})$.

followings. Body much larger, body length $13.0 \mathrm{~mm}$. Upper $1 / 3$ and posterior part of mesopleuron with dense micropunctures. Sublateral carina of propodeal dorsum more strongly raised and joining with lateral carina.

Male. Unknown.

Etymology. Named after fuscous wings.

Distribution. Korea, Japan.

Remarks. This species is very similar to T. popilliavora in general habitus. However, it is easily distinguished from the latter by the following characteristics: 1) lacking of longitudinal groove in mandible; 2) straight and well developed sublateral propodeal carina (in popilliavora weak and roundly bent posteriorly along margin of post-spiracle excavation); and 3) presence of polished impunctate area emarginated in posteromedian part of punctate area of pygidium (in popilliavora the emargination lacking).

1*Tiphia antigenata Allen and Jaynes (Fig. 2)

Tiphia antigenata Allen and Jaynes, 1930: 15 (in key), 18

(in key), 23-26 (우, TL: Kiangsu, China [USNM]).

Tiphia ogurai Tsuneki, 1986: 3 (우, TL: Seoul, Korea

[MNHAH]), new synonym.
Specimens examined. 1 우, Seoul, Korea, 16 Jul. 1943 (K. Tsuneki) (holotye of T. ogurai); 1 우, Yeonha-ri, Noeunmyeon, Chungju-si, Chungcheongbul-do, Korea, 25 Jul. 2006 (S.P. Han).

Redescription. Female. Body length $8.5 \mathrm{~mm}$ (Fig. 2A). Clypeus with its lateral apical margin distinctly convex; median apical production trapezium in shape, and its apical margin almost truncate (Fig. 2B). Frontal groove lacking. Pronotal carina well developed, at most weakened in dorsomedian part. Central longitudinal groove of pronotal lateral face defined, but intermittent, not forming a continual groove (Fig. 2F). Posterior margin of tegula without impressed line. Mesopleuron with a well-developed premarginal groove along its posterior border (Fig. $2 \mathrm{H}$, arrow); epicnemial carina strong (highly raised) and complete without interruption. Propodeal areola convergent, BAWL $1: 0.6: 1.5$; median carina present in basal half to $2 / 3$ of areola (Fig. $2 \mathrm{G}$ ); sublateral carina of propodeal dorsum roundly bent posteriorly, and bordering post-spiracle excavation; post-spiracle excavation roundish and deep. Median carina of propodeal posterior face short, being developed in lower half of the face. Metasomal tergum I folded subapically (Fig. 2E, arrow). Sternum I with lateral grooves in its posterior half, and me-

\footnotetext{
$1 *$ 꼬마굼벵 이벌
} 
dian carina absent. Lower margin of longer apical spine of hind tibia angled in basal 1/3; shorter one normal spine-like, $2 / 3$ as long as longer one. Hind basitarsus without groove; outer face of hind basitarsus with two straight, lanceolate spines excluding apical one. Wing as in fig. 2D: entirely bright brownish, and second intercubital vein sinuous.

Vertex and upper frons moderately punctuate, the punctures on the latter partially irregular. Upper portion of lower frons with sparse large punctures; lower portion of lower frons with dense small punctures smaller than those on upper portion. Clypeus with dense punctures except for impunctate median apical part. Basal two-thirds of pronotal dorsum with dense punctures, and the remaining apical part impunctate and polished; upper half of pronotal lateral face, except for puncture row set in upper marginal part, microcoriaceous, and lower half finely carinate. Tegula smooth and polished. Mesopleuron sparsely bipunctate with large and minute punctures, and the interspaces microcoriaceous. Mesoscutum and scutellum sparsely punctate. Metanotum bipunctate, with large and minute punctures, the minute punctures dense in its posterior part (Fig. 2K). Propodeal dorsum excluding areola microcoriaceous, with feeble sparse punctures; upper portion of propodeal lateral face with parallel carinae, and lower portion microcoriaceous. Metasomal tergum I folded preapically; normal preapical puncture band absent, at most puncture row composed of minute punctures present in lateral part of tergal disk behind the folding. Tergum II with sparse shallow punctures. Terga III$\mathrm{V}$, except apical marginal parts, very densely punctuate (Fig. $2 J)$. Basal half of pygidium sparsely to moderately punctate, and almost smooth in the remaining part at most weakly shagreened and sparsely ridged (Fig. 2C).

Body covered with whitish bristles and hairs; terga III-IV with sparse (mainly distribute in median part of each tergum) short brown bristles, in addition to longer whitish bristles and hairs (Fig. 2I, arrow). Body black. But mid and hind femora and tibiae reddish black. Mandible reddish brown.

Male. Unavailable for this study.

Distribution. China (Kiangsu, Kuliang), Korea (new record). Remarks. This species is a members of "koreana-group" (Allen et Jaynes, 1930) which comprises eight species in the
Far East and might be characterized by the combination of following characteristics: 1) mesopleuron with a well-developed premarginal groove along its posterior border; 2) metasomal tergum I folded subapically; and 3) terga III-IV with short brown bristles in addition to longer whitish bristles (Fig. 2I). According to the original description, this species is unusual in having much fewer brownish bristles on terga III-IV. After careful comparison with original description, we have come to a conclusion that the two Korean specimens including holotype of T. ogurai are conspecific to Tiphia antigenata Allen and Jaynes.

\section{ACKNOWLEDGEMENTS}

We would like to express our cordial thanks to Dr. Seiki Yamane (Kagoshima Unversity) for the loan and permission of publication of the Japanese specimen (used herein as paratype). We also thank Dr. Yoshiaki Hashiomoto (The Mus. Nat. Hum. Act., Hyogo) for making the holotype of $T$. ogurai available to us. This work was supported by the Korean Research Foundation grant (KRF-2006-353-C0042).

\section{REFERENCES}

Allen, H.W. and H.A. Jaynes, 1930. Contribution to the taxonomy of Asiatic wasps of the genus Tiphia (Scoiidae). Proc. U. S. Nat. Mus., 76(17): 1-105, pls. 1-4.

Han, S.P., S.G. Lee and J.K. Kim, 2007. A newly recorded species of the genus Tiphia Fabricius (Tiphiidae, Hymenoptera) from Korea, with a checklist of Korean Tiphiidae. J. AsiaPacific Entomol., 10(4): 307-311.

Kim, J.K. and S.P. Han, 2008. Description of a new species of the genus Tiphia (Tiphiidae, Hymenoptera) from Korea. Korean J. Syst. Zool., 24(2): 225-227.

Tsuneki, K., 1986. New species and subspecies of the Aculeata Hymenoptera from East Asia, with some synonyms, specific remarks and distributional data. SPJHA, 32: 1-60.

Received October 29, 2008 Accepted November 15, 2008 